\title{
Ablation of amorphous Polyethy (ethyl)letone (PEEK) by a femtosecond Ti:sapphire laser
}

DOI:

https://doi.org/10.1117/12.2543735

\section{Document Version}

Accepted author manuscript

Link to publication record in Manchester Research Explorer

\section{Citation for published version (APA):}

Li, Q., Perrie, W., Tang, Y., Allegre, O., \& Li, Z. (2020). Ablation of amorphous Polyethy (ethyl)letone (PEEK) by a femtosecond Ti:sapphire laser. In Proceedings of SPIE (Vol. 11268, pp. 112680L)

https://doi.org/10.1117/12.2543735

\section{Published in:}

Proceedings of SPIE

\section{Citing this paper}

Please note that where the full-text provided on Manchester Research Explorer is the Author Accepted Manuscript or Proof version this may differ from the final Published version. If citing, it is advised that you check and use the publisher's definitive version.

\section{General rights}

Copyright and moral rights for the publications made accessible in the Research Explorer are retained by the authors and/or other copyright owners and it is a condition of accessing publications that users recognise and abide by the legal requirements associated with these rights.

\section{Takedown policy}

If you believe that this document breaches copyright please refer to the University of Manchester's Takedown Procedures [http://man.ac.uk/04Y6Bo] or contact uml.scholarlycommunications@manchester.ac.uk providing relevant details, so we can investigate your claim.

\section{OPEN ACCESS}




\section{Ablation of amorphous Polyethy (ethyl)letone (PEEK) by a femtosecond Ti:sapphire laser}

Li, Qianliang, Perrie, Walter, Tang, Yue, Allegre, Olivier, Ho, Janet, et al.

Qianliang Li, Walter Perrie, Yue Tang, Olivier Allegre, Janet Ho, Paul Chalker, Zhaoging Li, Stuart P. Edwardson, Geoff Dearden, "Ablation of amorphous Polyethy(ethyl)letone (PEEK) by a femtosecond Ti:sapphire laser," Proc. SPIE 11268, Laser-based Micro- and Nanoprocessing XIV, 112680L (2 March 2020); doi: $10.1117 / 12.2543735$

SPIE. Event: SPIE LASE, 2020, San Francisco, California, United States 


\title{
Ablation of amorphous Polyethy(ethyl)letone (PEEK) by a femtosecond Ti:sapphire laser
}

\author{
Qianliang Li*a, Walter Perrie ${ }^{\mathrm{a}}$, Yue Tang a , Olivier Allegre ${ }^{\mathrm{b}}$, Janet $\mathrm{Ho}^{\mathrm{c}}$, Paul Chalker ${ }^{\mathrm{d}}$, Zhaoqing $\mathrm{Li}^{\mathrm{b}}$, \\ Stuart P Edwardson ${ }^{\mathrm{a}}$, Geoff Dearden ${ }^{\mathrm{a}}$ \\ aLaser Group, School of Engineering, Brownlow Street, University of Liverpool, Liverpool, L69 \\ 3GQ, United Kingdom; ${ }^{b}$ Laser Processing Research Centre, School of Mechanical, Aerospace and \\ Civil Engineering, The University of Manchester, Manchester M13 9PL, United Kingdom; \\ 'Electrochemistry Branch, US Army Research Laboratory, Adelphi, MD 20783; d Department of \\ Mechanical, Materials and Aerospace Engineering, School of Engineering, University of Liverpool, \\ Liverpool, L69 3GQ, United Kingdom.
}

\begin{abstract}
Laser micro-machining of amorphous PEEK has been demonstrated with $180 \mathrm{fs} / 1 \mathrm{kHz}$ NIR (775 nm) and NUV (387 $\mathrm{nm}$ ) laser pulses. The single pulse ablation threshold was found to be $2.01 \pm 0.05 \mathrm{~J} / \mathrm{cm}^{2}$ and $0.23 \pm 0.02 \mathrm{~J} / \mathrm{cm}^{2}$ at $775 \mathrm{~nm}$ and $387 \mathrm{~nm}$ respectively. The significant difference in ablation threshold is due to the requirement for 3-photon absorption at $775 \mathrm{~nm}$, where PEEK is transparent while significant linear absorption within the material bandgap occurs at $387 \mathrm{~nm}$, enhancing 2-photon absorption. A high 2-photon absorption coefficient, measured to be $\beta_{387} \sim 38 \mathrm{~cm} \mathrm{GW}^{-1}$ supports this view while at the bandgap edge, $400 \mathrm{~nm}, \beta_{400} \sim 0.7 \mathrm{~cm} \mathrm{GW}^{-1}$. Multi-pulse exposure yields incubation coefficients of $S_{775}=0.72 \pm 0.01$ and $S_{387}=0.85 \pm 0.02$ hence incubation is significantly reduced in the NUV. Ablation of PEEK with NUV fs pulses demonstrates much reduced melting and re-deposition, thus precision NUV polymer micromachining is accomplished while laser induced periodic surface structures (LIPSS) with pitch $\Lambda<0.4 \mu \mathrm{m}$ are observed at the base of ablated regions. Scanned areas exhibit white light diffraction due to this sub-micron periodic surface modulation. With the aid of a phase only spatial light modulator, multi-beam NUV micro-structuring is achieved, speeding micro-processing while reaching a line width $<4 \mu \mathrm{m}$ with $\mathrm{NA}=0.4$ objective.
\end{abstract}

Keywords: PEEK, Femtosecond pulsed laser, Micro-machining, Ablation threshold, Incubation effect, Nonlinear absorption.

\section{INTRODUCTION}

Polyether ether ketone (PEEK) is a high performance thermoplastic polymer with outstanding mechanical and chemical properties, high temperature resistance and good biocompatibility for medical applications ${ }^{1-4}$. Therefore, PEEK is widely used in electronics, medicine and surgery, aerospace and automotive ${ }^{1,2,5}$. Tribological property modification and periodic structuring of PEEK surfaces (amorphous and semi-crystalline) using femtosecond infrared pulses were recently investigated ${ }^{6,7}$ with the window for creating LIPSS very narrow.

Topography modification of PEEK surfaces can achieve desired surface properties, such as improved wettability ${ }^{4}$. Processing methods include chemical etching and plasma treatments, however, aromaticity within the polymer backbone may offset the etching in plasma treatments ${ }^{8}$. Chemical etching may also damage the surface layer ${ }^{9}$. Therefore, laser processing offers a promising tool for highly specific, high resolution treatments ${ }^{10}$. Femtosecond laser pulses provide negligible heat diffusion zones and minimised energy loss for machining polymer surfaces ${ }^{11}$. High intensity fs lasers can generate multiphoton induced ablation and ionization ${ }^{12,13}$ in transparent substrates.

The purpose of the study presented here is to investigate and compare the ablation threshold, incubation and optical properties (linear and nonlinear absorption) of amorphous PEEK films at both $775 \mathrm{~nm}$ and $387 \mathrm{~nm}$. In the NIR, PEEK is transparent so that excitation proceeds through true multi-photon absorption - while at $387 \mathrm{~nm}$ within the band edge, linear absorption also occurs so that at ultrahigh intensity, reverse saturated absorption (RSA) is the likely NL mechanism in the NUV. 


\section{EXPERIMENTAL SETUP}

\subsection{Material}

The material used was amorphous PEEK (25, 50, 100 and $200 \mu \mathrm{m}$ thick, Goodfellow). While the $25 \mu \mathrm{m}$ and $50 \mu \mathrm{m}$ films had optically flat surfaces, thicker films required optical polishing. Prior to experiments, the PEEK samples were cleaned in methanol with an ultrasonic treatment for 5 minutes.

\subsection{Laser processing}

Figure 1 shows the scheme of the femtosecond laser system and optical setup. A Titanium-sapphire laser system (ClarkMXR CPA 2010) provides a pulse energy of $1 \mathrm{~mJ}$ at $1 \mathrm{kHz}$ with pulse duration of $180 \mathrm{fs}$ at $775 \mathrm{~nm}\left(\mathrm{M}^{2} \sim 1.3\right)$. For NIR ablation, the sample was set perpendicular to the laser beam on an Aerotech micro position translation stage (x, $\mathrm{y}, \mathrm{z}$ and $\theta$ ) and the attenuated beam, expanded by $\times 3$ then directed to a Nutfield XLR8 scan head with $100 \mathrm{~mm} f$ theta lens. After a beams splitter, the transmitted component at $775 \mathrm{~nm}$ NIR light was attenuated (Diffractive Optic Attenuator, DOA, TOPAG), reflected from a phase only SLM (Hamamatsu X10468-02) and then frequency-doubled to generate $387 \mathrm{~nm}$ NUV wavelength in a thin, $0.6 \mathrm{~mm}$ thick Beta Barium Borate (BBO) crystal. All treatment was conducted in air at atmospheric pressure. The pulse energy was measured by a Molectron pyroelectric detector (3Sigma) over an average of 5000 pulses.

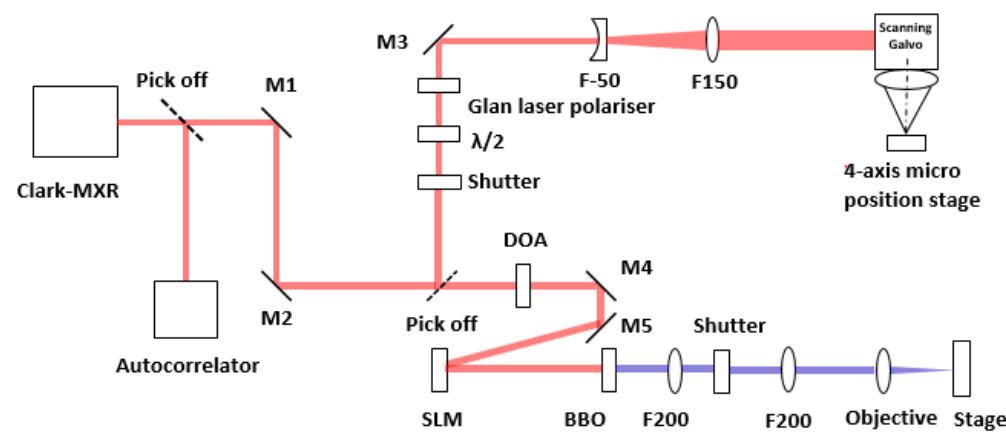

Figure 1. Scheme of laser system and experimental set-up. There are two beam lines for $775 \mathrm{~nm}$ and $387 \mathrm{~nm}$ processing.

\subsection{Surface characterization}

Laser-processed samples were examined by optical microscopy (Nikon), white light interferometry (WYKO NT1100), SEM and XRD.

\section{RESULTS AND DISCUSSION}

\subsection{Ablation threshold}

The experiment was performed with a different number of laser shots (1, 20, 50 and 100 pulses) over a range of pulse energies (figure 2). The peak laser fluence was calculated by the equation:

$$
F=\frac{2 E}{\pi \omega_{0}^{2}}
$$

where $\mathrm{E}$ is the incident energy per pulse, and $\omega_{0}$ is the waist radius of the focal spot. The squared diameters of the ablated area are related to the laser fluence by the following equation ${ }^{14}$ :

$$
D^{2}=2 \omega_{0}^{2} \ln \frac{F}{F_{\text {th }}}
$$


where $\mathrm{D}$ is the diameter of the spot ablated on PEEK, and $\mathrm{F}_{\mathrm{th}}$ is the ablation threshold of the material.
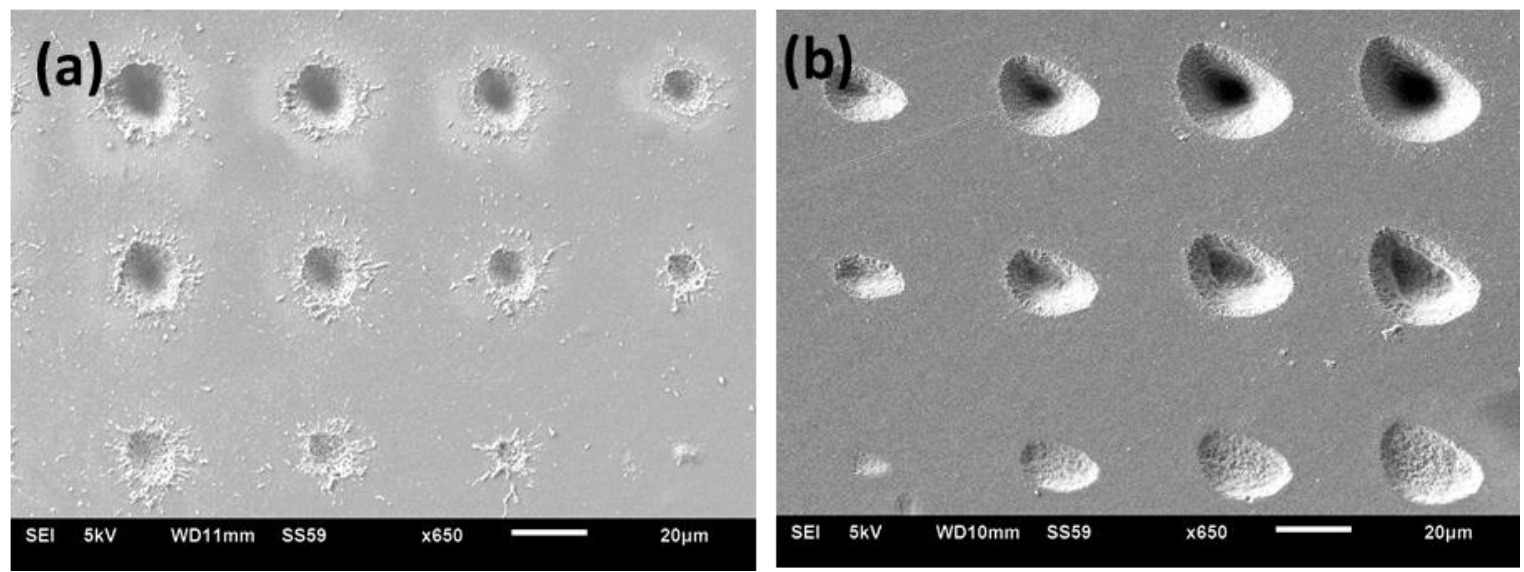

Figure 2. (a) SEM micrograph image of ablation spots on PEEK at $775 \mathrm{~nm}$ with $100 \mathrm{~mm}$-theta lens. From right to left, Fluence F= $0.94,1.21,1.48,1.75 \mathrm{~J} \mathrm{~cm}^{-2}$, from top to bottom: 100, 50, 20 pulses. Note the significant re-deposition of melted debris around the craters (b) SEM micrograph image of ablation spots at $387 \mathrm{~nm}$ with objective focal length $\mathrm{f}=100 \mathrm{~mm}$. From left to right: Fluence $\mathrm{F}=0.18,0.26,0.36,0.44 \mathrm{~J} \mathrm{~cm}^{-2}$, from top to bottom: 100, 50, 20 pulses. Ablation is much superior with almost no re-deposition.

Figure 3 shows a plot of squared diameter against lnE yielding the ablation thresholds for both $775 \mathrm{~nm}$ and $387 \mathrm{~nm}$. The fits to equation (2) are satisfactory. The single pulse ablation threshold was found to be $2.01 \pm 0.05 \mathrm{~J} \mathrm{~cm}^{-2}$ at $775 \mathrm{~nm}$ compared to $0.23 \pm 0.02 \mathrm{~J} \mathrm{~cm}^{-2}$ at $387 \mathrm{~nm}$, a significant reduction in the NUV. The ablation thresholds reduce with pulse number, indicating that incubation occurs.
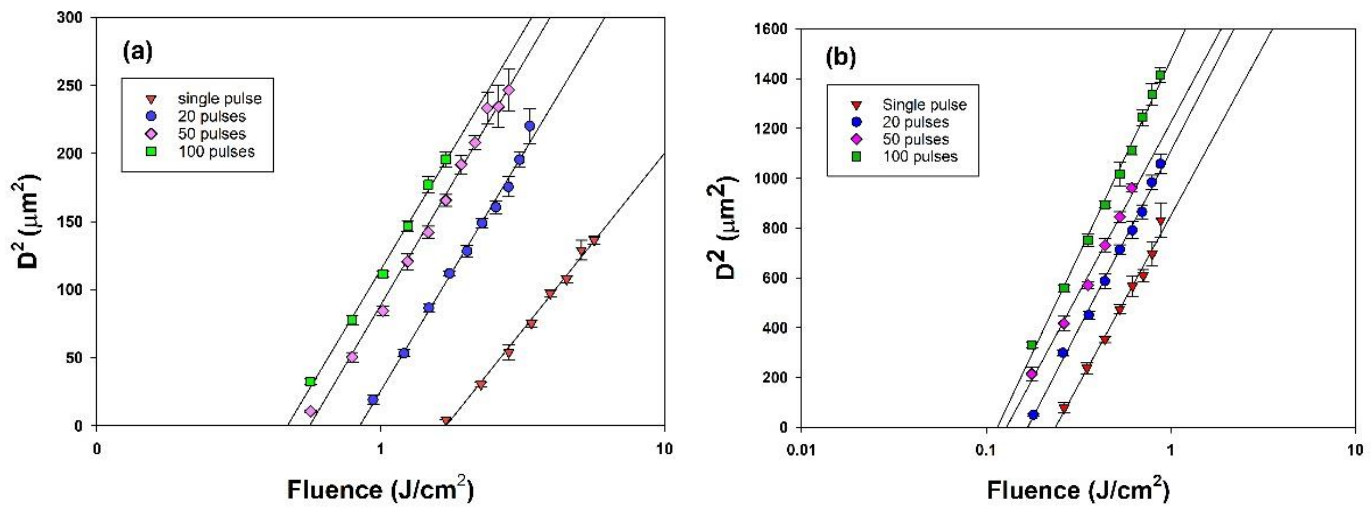

Figure 3. $\mathrm{D}^{2}$ versus Fluence for 1, 20, 50 and 100 pulses. (a) $775 \mathrm{~nm}$, (b) $387 \mathrm{~nm}$.

\subsection{Incubation coefficient}

Figure 4 (a) plots the threshold fluence versus at both wavelengths with the number of applied pulses, highlighting incubation or the variation of threshold with exposure. According to the incubation model proposed by Jee ${ }^{15}, \mathrm{~F}_{\text {th }}(\mathrm{N})$ can be described by,

$$
F_{\text {th }}(N)=F_{\text {th }}(1) \times N^{S-1}
$$

where $\mathrm{S}$ is the so-called incubation coefficient and $\mathrm{F}_{\mathrm{th}}(1)$ is the ablation threshold for $\mathrm{N}=1$.

The equation can be expressed in the following form: 


$$
\ln \left[N F_{\mathrm{th}}(N)\right]=S \ln (N)+\ln \left[F_{\mathrm{th}}(1)\right]
$$

Figure 4 (b) shows the data plotted in this manner from which the incubation coefficients are $S_{775}=0.72$ while $S_{387}=$ 0.85 hence incubation is much reduced in the NUV. The value at $387 \mathrm{~nm}$ is close to that of a number of metals ${ }^{16}$. It can also be inferred that incubation effectively saturates when $\mathrm{N}>100$. The solid line represents a least square fit to the equation (4).

Incubation therefore plays an important role in multi-pulse micro machining on PEEK using a femtosecond pulsed laser at both $775 \mathrm{~nm}$ and $387 \mathrm{~nm}$ but significantly reduced in the NUV. Incubation in PEEK is likely due to the chemical composition change, especially at $775 \mathrm{~nm}$ - and developing surface roughness.
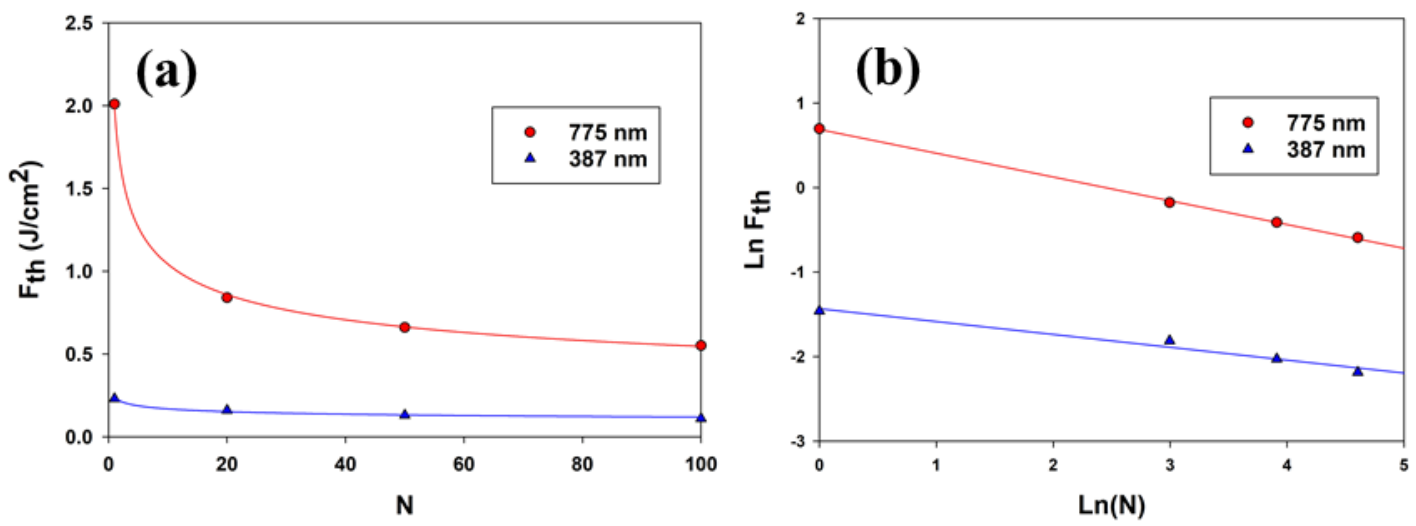

Figure 4. (a) Laser damage (ablation) threshold fluence $\mathrm{F}_{\text {th }}$ as a function of the number $\mathrm{N}$ of pulses for amorphous PEEK. (b) Plot of logarithm functions of threshold fluence $\mathrm{F}_{\text {th }}$ and the number $\mathrm{N}$ of pulses for amorphous PEEK.

\subsection{Absorption coefficient}

Figure 5 shows the transmission of PEEK as a function of film thickness measured with a low energy collimated beams at $775 \mathrm{~nm}, 387 \mathrm{~nm}$ and for comparison, $400 \mathrm{~nm}$ just on the band edge. Light will be attenuated when passing through the material according to the Beer-Lambert Law, which, allowing for reflection losses, gives

$$
I_{(z)}=I_{0}(1-R)^{2} e^{-\alpha z}
$$

where $\mathrm{I}(\mathrm{z})$ is the transmitted intensity, $\mathrm{I}_{0}$ is the incident intensity, $\alpha$ is the absorption coefficient $\left(\mathrm{cm}^{-1}\right)$, and $\mathrm{z}$ is the material depth $(\mathrm{cm})$.

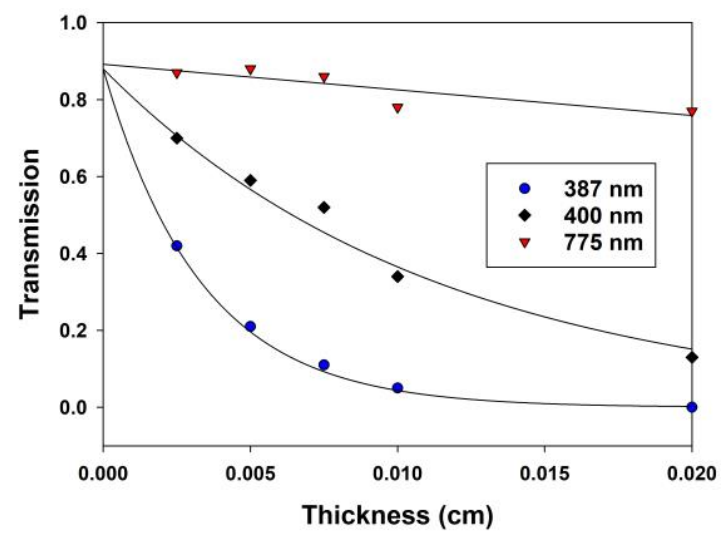

Figure 5. Linear absorption of amorphous PEEK at 387, 400 and $775 \mathrm{~nm}$ with film thickness. Exponential fits at 387 and $400 \mathrm{~nm}$ yield linear absorption coefficients of $300 \mathrm{~cm}^{-1}$ and $80 \mathrm{~cm}^{-1}$ respectively. At $775 \mathrm{~nm}, \alpha \sim 6.4 \mathrm{~cm}^{-1}$, essentially transparent. 
Assuming for the moment that absorption is negligible, the theoretical transmission $T_{\mathrm{th}}=(1-\mathrm{R})^{2}=0.88$, where the reflection per face $\mathrm{R}=(\mathrm{n}-1)^{2} /(\mathrm{n}+1)^{2}=0.06$ from the Fresnel equation ${ }^{17}, \mathrm{n}$ (PEEK) $=1.65^{18}$, in agreement with that observed at $\mathrm{z}=0$.

Non-linear absorption was measured simply by varying incident intensity on the films and measuring transmission, figure 6, which highlights NL absorption on the $25 \mu \mathrm{m}$ film at $387 \mathrm{~nm}$ - even at a few $\mathrm{GW} \mathrm{cm}^{-2}$. When both linear and NL absorption occur in a material, the transmission is given by ${ }^{19}$,

$$
T=(1-R)^{2} \frac{\alpha_{0} \exp \left(-\alpha_{0} z\right)}{\alpha_{0}+\beta I_{0}\left[1-\exp \left(-\alpha_{0} z\right)\right]}
$$

where $\beta$ is the 2-photon absorption coefficient. By plotting this function, setting $\alpha_{0}=300 \mathrm{~cm}^{-1}$ and $\mathrm{z}=2.5 \times 10^{-3} \mathrm{~cm}$, the best fit yields $\beta_{(387)}=38 \mathrm{~cm} \mathrm{GW}^{-1}$, a high value. Note that in this intensity range, the function is nearly linear. With this $\beta$, the effective coupling depth $\mathrm{d} \sim 1 / \beta \mathrm{I}$ with a $1 \mu \mathrm{J}, 200 \mathrm{fs}$ pulse focused to a $30 \mu \mathrm{m}$ spot gives $\mathrm{d} \sim 100 \mathrm{~nm}$, consistent with observations of ablation rate per pulse.

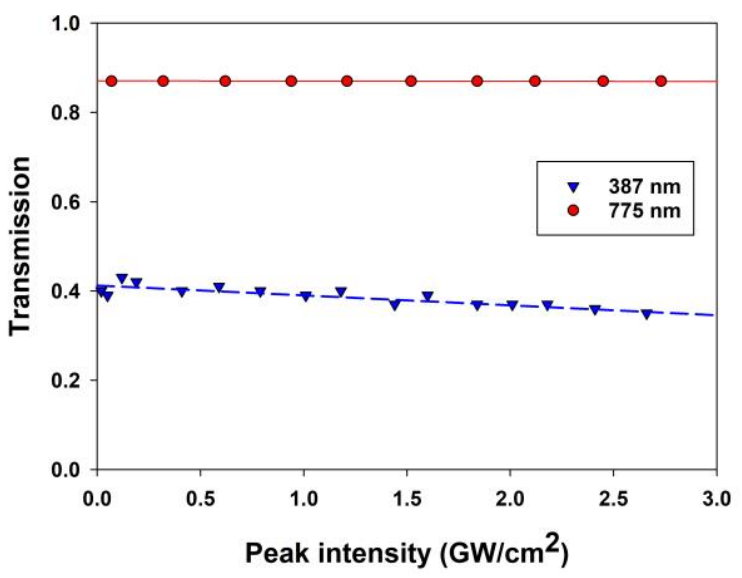

Figure 6. Transmission as a function of incident intensity of $25 \mu \mathrm{m}$ PEEK film.

The photon energy at $775 \mathrm{~nm}$ is $\mathrm{h} v=1.6 \mathrm{eV}$. As the band gap of PEEK is $\sim 3.2 \mathrm{eV}$, NL two photon absorption is required to excite electrons to the lowest levels of the conduction band. Figure 7 shows the calculated band structure (density of states) in PEEK based on a QM model of the molecular polymer structure ${ }^{20}$. Once excited to the conduction band via NL absorption, further sequential photon absorption will occur due to the much higher density of states at 4.8 $\mathrm{eV}$ (3-photon) at $775 \mathrm{~nm}$. At $387 \mathrm{~nm}$, (hv = 3.2 eV) single and sequential two photon absorption will occur as a high density of states is available for the second photon at $387 \mathrm{~nm}$ absorption. As intensity increases, the much higher absorption cross section for excited state absorption will rapidly populate states at $6.4 \mathrm{eV}$. Hence, instead of normal saturation, absorption increases with intensity, or Reverse Saturation Absorption (RSA) ${ }^{21}$. This excitation energy is able to break almost all the bonds in the polymer directly and consistent with the clean ablation observed with little thermal effect. Further work using the Z-scan technique (not presented here) confirmed that $\beta$ is intensity dependent - indicating that RSA is indeed relevant. In the DOS calculations, Carbon atoms contribute mostly to the density of states. The transitions from valence band to conduction band near $3.2 \mathrm{eV}$ is due to the degenerate $\mathrm{e}_{1 \mathrm{~g}}$ electronic levels of benzene ${ }^{22}$. 


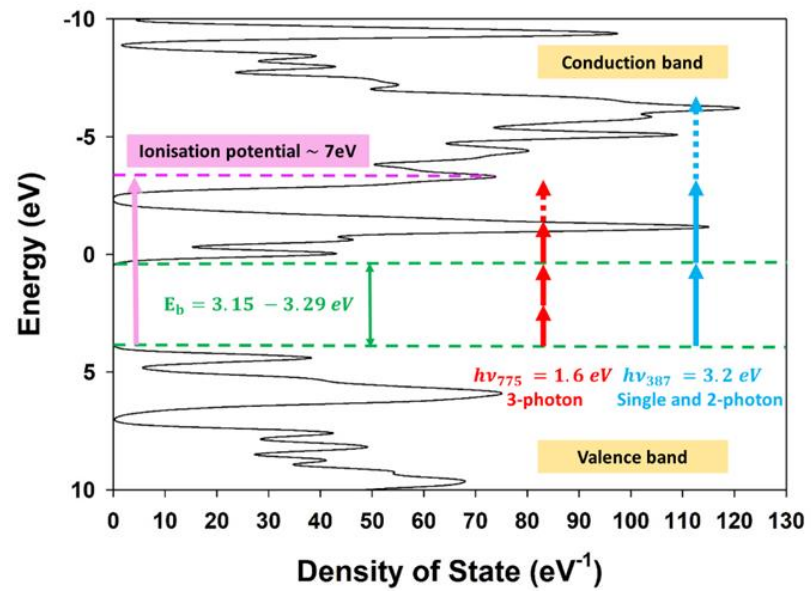

Figure 7. Band energy diagram (density of states) of PEEK and multi-photon absorption scheme. The density of states was calculated theoretically by $\mathrm{J}$ Ho et $\mathrm{al}^{20}$.

\subsection{Laser Induced Periodic Surface Structuring (LIPSS)}

Near threshold laser ablation can generate laser induced periodic surface structures due to the interference of surface scattered waves with the incoming radiation ${ }^{23}$. The resulting modulation of electron density creates periodic surface profile modulation with a pitch close to the incident wavelength. Figure 8 (a) shows an SEM image of these low frequency LIPSS on $50 \mu \mathrm{m}$ thick PEEK $\left(\mathrm{F}=0.52 \mathrm{~J} \mathrm{~cm}^{-2}\right.$, scan speed $\left.=3 \mathrm{~mm} \mathrm{~s}^{-1}\right)$. The direction of these low frequency LIPSS was parallel to the incident electric field. This ripple orientation is typical for dielectrics and polymers, while metals often show perpendicular direction LIPSS. White light diffraction of larger area LIPSS is displayed in figure 8 (b) (c).
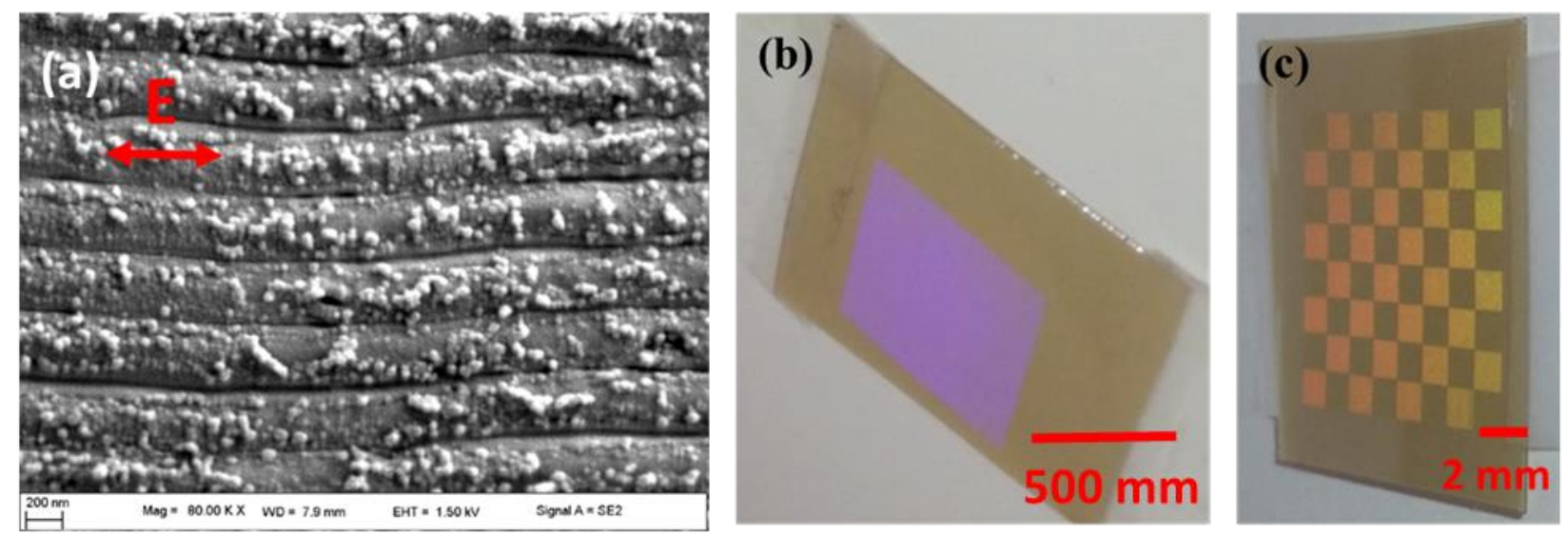

Figure 8. (a) SEM image of LIPSS on amorphous PEEK at $387 \mathrm{~nm}$. Note the presence of nano-particles with sizes $<50 \mathrm{~nm}$ (b) White light diffraction from LIPSS on $200 \mu \mathrm{m}$ thick PEEK $\left(\mathrm{F}=0.52 \mathrm{~J} \mathrm{~cm}^{-2}, 1\right.$ overscan). (c) High angle WL diffraction from chessboard pattern $\left(\mathrm{F}=0.52 \mathrm{~J} \mathrm{~cm}^{-2}, \mathrm{f}=100 \mathrm{~mm}\right)$ by rotating linear polarization between squares.

\subsection{NUV Parallel processing}

Parallel processing can speed fabrication during micro-machining. With appropriate computer generated holograms CGHs applied to an SLM (Hamamatsu X10468-02), parallel NIR beams at $775 \mathrm{~nm}$ were frequency doubled to NUV beams in a thin $\mathrm{BBO}$ crystal. With a higher $\mathrm{NA}=0.4$ objective, fine lines width $\sim 4-6 \mu \mathrm{m}$ on $10 \mu \mathrm{m}$ pitch were machined in parallel on PEEK is shown in figure 9. Scan speed here was $1 \mathrm{~mm} \mathrm{~s}^{-1}$ with fluence $\mathrm{F}=1.16 \mathrm{~J} \mathrm{~cm}^{-2}$. Uniformity can be improved with the addition of a feedback system. 


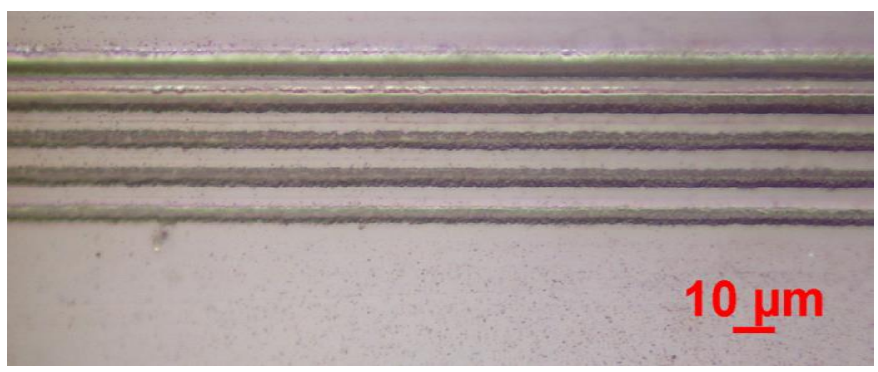

Figure 9. Parallel micro-structures machined on amorphous PEEK at $387 \mathrm{~nm}$ with line width of $\sim 4-6 \mu \mathrm{m}, \mathrm{NA}=0.4$. Scan speed $\mathrm{s}=1$ $\mathrm{mm} \mathrm{s}^{-1}$ with fluence $\mathrm{F}=1.16 \mathrm{~J} \mathrm{~cm}^{-2}$.

\subsection{XRD spectrum}

Bulk PEEK can have a significant semi-crystalline structure and is often opaque. The thin films used here were supplied as "amorphous" hence we checked the micro-structure using XRD (Rigaku MiniFlex). Figure 10 shows the XRD spectrum of the $100 \mu \mathrm{m}$ amorphous PEEK film and typical of the XRD spectra obtained on various film thicknesses. There are no sharp peaks, characteristic of a semi-crystalline phase but only a broad feature which is due to X-ray fluorescence. The films used are indeed mainly amorphous. If a semi-crystalline component exists, then it is at the few $\%$ levelel ${ }^{7}$.

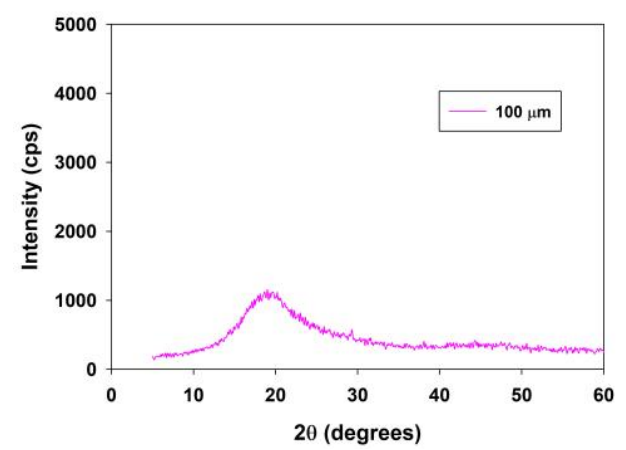

Figure 10. XRD spectrum of $100 \mu \mathrm{m}$ amorphous PEEK.

\section{CONCLUSION}

Amorphous PEEK films can be ablated with ultrahigh intensity fs laser pulses at $775 \mathrm{~nm}$, where the material is transparent and with much better precision at $387 \mathrm{~nm}$ just within the band edge. For single pulse, the ablation threshold is $2.01 \mathrm{~J} \mathrm{~cm}^{-2}$ and $0.23 \mathrm{~J} \mathrm{~cm}^{-2}$ respectively, the much lower threshold at $387 \mathrm{~nm}$ evidence of a much more efficient NL absorption mechanism. As linear absorption is negligible at $775 \mathrm{~nm},\left(\alpha=6.4 \mathrm{~cm}^{-1}\right)$, ablation takes place through nonlinear two photon absorption followed by sequential photon absorption. Incubation is significant and results in a significant thermal effect, causing sub-surface carbonization of the material below ablation threshold while above ablation threshold, significant re-deposition was observed with melted debris around the craters. On the contrary, at 387 $\mathrm{nm}$, ultrahigh intensity ablation was much cleaner, with the single pulse ablation threshold reduced by almost one order of magnitude. With a photon energy just inside the material bandgap, single and sequential photon absorption occur within the temporal pulse length and as intensity is increased, the high cross section for excited state absorption causing reverse saturation (RSA) dominates the NL absorption process. A high level of electron excitation in the conduction band with at least $6.4 \mathrm{eV}$ is able to break almost all the polymer bonds directly, reminiscent of UV excimer ablation. The ability to micro-structure LIPSS becomes relatively easy with ultrahigh intensity $387 \mathrm{~nm}$ pulses since the absorption depth reduces to $\sim 100 \mathrm{~nm}$. These LIPSS may yet prove useful in medical applications, such as cell culture by improving cell attachment in spinal implants ${ }^{1}$. 


\section{REFERENCES}

[1] Kurtz, S. M. and Devine, J. N., "PEEK biomaterials in trauma, orthopedic, and spinal implants," Biomaterials 28(32), 4845-4869 (2007).

[2] Hoskins, T. J., Dearn, K. D., Chen, Y. K. and Kukureka, S. N., "The wear of PEEK in rolling-sliding contactSimulation of polymer gear applications," Wear 309(1-2), 35-42 (2014).

[3] Williams, D. F., McNamara, A. and Turner, R. M., "Potential of polyetheretherketone (PEEK) and carbon-fibrereinforced PEEK in medical applications," Journal of Materials Science Letters 6(2), 188-190 (1987).

[4] Riveiro, A., Soto, R., Comesana, R., Boutinguiza, M. d, Del Val, J., Quintero, F., Lusquiños, F. and Pou, J., "Laser surface modification of PEEK," Applied Surface Science 258(23), 9437-9442 (2012).

[5] Dahan, N., Donaldson, N., Taylor, S. and Sereno, N., "The application of PEEK to the packaging of implantable electronic devices: water permeation calculation method and maximum achievable lifetime with desiccant," Journal of microelectronics and electronic packaging 10(1), 15-22 (2013).

[6] Hammouti, S., Pascale-Hamri, A., Faure, N., Beaugiraud, B., Guibert, M., Mauclair, C., Benayoun, S. and Valette, S., "Wear rate control of peek surfaces modified by femtosecond laser," Applied Surface Science 357, 1541-1551 (2015).

[7] Hammouti, S., Beaugiraud, B., Salvia, M., Mauclair, C., Pascale-Hamri, A., Benayoun, S. and Valette, S., "Elaboration of submicron structures on PEEK polymer by femtosecond laser," Applied Surface Science 327, 277-287 (2015).

[8] France, R. M. and Short, R. D., "Plasma treatment of polymers: the effects of energy transfer from an argon plasma on the surface chemistry of polystyrene, and polypropylene. A high-energy resolution X-ray photoelectron spectroscopy study," Langmuir 14(17), 4827-4835 (1998).

[9] Ha, S.-W., Hauert, R., Ernst, K.-H. and Wintermantel, E., "Surface analysis of chemically-etched and plasmatreated polyetheretherketone (PEEK) for biomedical applications," Surface and coatings technology 96(2-3), 293-299 (1997).

[10] Laurens, P., Sadras, B., Decobert, F., Arefi-Khonsari, F. and Amouroux, J., "Laser-induced surface modifications of poly (ether ether ketone): influence of the excimer laser wavelength," Journal of adhesion science and technology 13(9), 983-997 (1999).

[11] Serafetinides, A. A., Makropoulou, M. I., Skordoulis, C. D. and Kar, A. K., "Ultra-short pulsed laser ablation of polymers," Applied surface science 180(1-2), 42-56 (2001).

[12] Okoshi, M. and Inoue, N., "Laser ablation of polymers using $395 \mathrm{~nm}$ and $790 \mathrm{~nm}$ femtosecond lasers," Applied Physics A 79(4-6), 841-844 (2004).

[13] Bityurin, N., "8 Studies on laser ablation of polymers," Annual Reports Section" C"(Physical Chemistry) 101, 216-247 (2005).

[14] Jandeleit, J., Urbasch, G., Hoffmann, H. D., Treusch, H.-G. and Kreutz, E. W., "Picosecond laser ablation of thin copper films," Applied Physics A 63(2), 117-121 (1996).

[15] Jee, Y., Becker, M. F. and Walser, R. M., "Laser-induced damage on single-crystal metal surfaces," JOSA B 5(3), 648-659 (1988).

[16] Kong, M. C. and Wang, J., "Surface quality analysis of titanium and nickel-based alloys using picosecond laser," Procedia CIRP 13, 417-422 (2014).

[17] Judd, D. B., "Fresnel reflection of diffusely incident light," J. Res. Natl. Bur. Stand 29(5), 329-332 (1942).

[18] Biron, M., [Material Selection for Thermoplastic Parts: Practical and Advanced Information], William Andrew (2015).

[19] Derkowska, B., Wojdyła, M., Płóciennik, P., Sahraoui, B. and Bała, W., "Linear and nonlinear optical properties of Zn1-xMgxSe layers grown by MBE and PLD methods," Opto-Electronics Review 12(4), 405-409 (2004).

[20] Ho, J., Olguin, M. and Diaz, C., "Poly (aryl-ether-ether-ketone) as a Possible Metalized Film Capacitor Dielectric: Accurate Description of the Band Gap Through Ab Initio Calculation," ARMY RESEARCH LAB ADELPHI MD SENSORS AND ELECTRON DEVICES DIRECTORATE (2014).

[21] Poornesh, P., Umesh, G., Hegde, P. K., Manjunatha, M. G., Manjunatha, K. B. and Adhikari, A. V., "Studies on third-order nonlinear optical properties and reverse saturable absorption in polythiophene/poly (methylmethacrylate) composites,” Applied Physics B 97(1), 117-124 (2009).

[22] Lazzaroni, R., Sato, N., Salaneck, W. R., Dos Santos, M. C., Brédas, J. L., Tooze, B. and Clark, D. T., "Electronic structure of poly (ether-ether-ketone), PEEK," Chemical physics letters 175(3), 175-181 (1990).

[23] Sipe, J. E., Young, J. F., Preston, J. S. and Van Driel, H. M., "Laser-induced periodic surface structure. I. 
Theory," Physical Review B 27(2), 1141 (1983).

Proc. of SPIE Vol. 11268 112680L-9

Downloaded From: https://www.spiedigitallibrary.org/conference-proceedings-of-spie on 17 Mar 2020 Terms of Use: https://www.spiedigitallibrary.org/terms-of-use 